\title{
The Adult Spinal Cord Harbors a Population of GFAP-Positive Progenitors with Limited Self-Renewal Potential
}

\author{
Roberto Fiorelli, ${ }^{1}$ Arantxa Cebrian-Silla, ${ }^{2}$ Jose-Manuel Garcia-Verdugo, ${ }^{2}$ \\ and Olivier Raineteau ${ }^{1}$
}

\begin{abstract}
Adult neural stem cells (aNSCs) of the forebrain are GFAP-expressing cells that are intercalated within ependymal cells of the subventricular zone (SVZ). Cells showing NSCs characteristics in vitro can also be isolated from the periaqueductal region in the adult spinal cord (SC), but contradicting results exist concerning their glial versus ependymal identity. We used an inducible transgenic mouse line (hGFAP-CreERT2) to conditionally label GFAP-expressing cells in the adult SVZ and SC periaqueduct, and directly and systematically compared their self-renewal and multipotential properties in vitro. We demonstrate that a population of $\mathrm{GFAP}^{+}$cells that share the morphology and the antigenic properties of SVZ-NSCs mostly reside in the dorsal aspect of the central canal (CC) throughout the spinal cord. These cells are non-proliferative in the intact spinal cord, but incorporate the S-phase marker EdU following spinal cord injury. Multipotent, clonal YFP-expressing neurospheres (i.e., deriving from recombined GFAP-expressing cells) were successfully obtained from both the intact and injured spinal cord. These spheres however showed limited self-renewal properties when compared with SVZ-neurospheres, even after spinal cord injury. Altogether, these results demonstrate that significant differences exist in NSCs lineages between neurogenic and nonneurogenic regions of the adult CNS. Thus, although we confirm that a population of multipotent GFAP ${ }^{+}$cells co-exists alongside with multipotent ependymal cells within the adult SC, we identify these cells as multipotent progenitors showing limited self-renewal properties.
\end{abstract}

Key Words: SVZ, neural stem cells, astrocytes, ependymal cells, spinal cord injury

GLIA 2013;61:2100-2113

\section{Introduction}

$\mathrm{D}$ uring the development of the vertebrate central nervous system (CNS), peri-ventricular radial glial (RG) cells self-renew through asymmetric division and sequentially give rise to neurons, ependymal cells, and glial cells throughout the brain (Anthony et al., 2004; Kriegstein and AlvarezBuylla, 2009). Lineage tracing studies at perinatal stages have revealed that RG transform into aNSCs that persist within the subventricular zone (SVZ) of the lateral ventricle and produce new neurons and glia throughout adulthood (Doetsch et al., 1999; Ganat et al., 2006; Lledo et al., 2008; Merkle et al., 2004). These adult neurogenic NSCs retain a number of radial glia properties, such as an expression of Glial Fibril- lary Acidic Protein (GFAP), Nestin, Vimentin, and BLBP (Doetsch et al., 1999) and the presence of an apical process contacting the lumen of the ventricle opposing a longer basal process (Mirzadeh et al., 2008). They can be isolated and cultured in vitro in the presence of mitotic factors, forming multipotent, self-renewing neurospheres (Golmohammadi et al., 2008; Weiss et al., 1996), while juxtaposed GFAP-negative ependymal cells fail to do so (Pfenninger et al., 2011).

Neurosphere-forming cells can also be isolated from non-neurogenic regions of the CNS, such as the spinal cord (Martens et al., 2002; Shihabuddin et al., 2000; Weiss et al., 1996). Notably, SC-derived neurospheres show in vitro multipotency and self-renewal properties identical to cultures

View this article online at wileyonlinelibrary.com. DOI: 10.1002/glia.22579

Published online October 7, 2013 in Wiley Online Library (wileyonlinelibrary.com). Received May 3, 2013, Accepted for publication Aug 28, 2013.

Address correspondence to Olivier Raineteau, University of Zurich, Brain Research Institute, Winterthurerstrasse 190, 8057 Zurich, Switzerland. E-mail: raineteau@hifo.uzh.ch

From the ${ }^{1}$ Brain Research Institute, University of Zurich/ETHZ, Switzerland; ${ }^{2}$ Laboratory of Comparative Neurobiology, Instituto Cavanilles de Biodiversidad y Biologia Evolutiva, University of Valencia, 46980, CIBERNED, Valencia, Spain. 
Fiorelli et al.: GFAP ${ }^{+}$Progenitors of the Adult Spinal Cord

prepared from the SVZ (Weiss et al., 1996). Furthermore, spinal cord injuries (SCI) greatly increase the yield of neurospheres-forming cells (Ohori et al., 2006; Yamamoto et al., 2001). These observations together with their obvious therapeutic potential (Hofstetter et al., 2005; Ohori et al., 2006; Yang et al., 2006), raised the interest to identify neurospheres-forming cells in the adult spinal cord. Microdissection of the SC central canal (CC) as well as fate mapping studies support a peri-acqueductal origin of NSCs, while they exclude a contribution of parenchymal glial cells to neurospheres formation (Barnabe-Heider et al., 2010; Martens et al., 2002; Sabourin et al., 2009). Unresolved issues however persist regarding the ependymal versus glial nature of neurosphere-forming cells in the spinal cord CC. While fate mapping studies concluded for an ependymal identity of SC sphere forming cells (Meletis et al., 2008), recent work highlighted the presence of GFAP-expressing cells intermingled with ependymal cells (Ecc) by fluorescent (Hamilton et al., 2009) as well by electron microscopy (Alfaro-Cervello et al., 2012). These GFAP-expressing cells present a basal process that contact the lumen of the central canal, and have therefore been defined as central canal-contacting astrocytes (i.e., Acc; Alfaro-Cervello et al., 2012).

Exploring similarities in the glial identity of neurosphere-forming cells in the adult SC and SVZ has so far been hampered by the use of distinct promoters to label and study these cells by transgenesis. Here, we used an inducible transgenic mouse model expressing CreERT2 under the human GFAP (hGFAP) promoter (Ganat et al., 2006) to directly and systematically compare the self-renewal and multipotent potential of GFAP-expressing cells isolated from these two regions. Using this transgenic approach, we show efficient recombination in a population of adult SVZ-NSCs as well as in a population of mainly non-proliferative Acc around the spinal cord CC. While these two cell populations display many morphological and antigenic similarities, our results highlight differences in their capacity to generate selfrenewing neurospheres in vitro, even after spinal cord injury.

Our work confirms the existence of GFAP-expressing cells (i.e., Acc cells) co-existing with ependymal cells in the spinal cord CC. These Acc participate to the generation of multipotent neurospheres, but show restricted self-renewal properties compared with Ecc-derived neurospheres or GFAPexpressing SVZ-NSCs, even after injury. These results highlight the heterogeneity of cell lineages showing NSCs properties along the adult CNS axis.

\section{Materials and Methods \\ Ethics Statement}

All experimental protocols were approved by the Veterinary Department of the Canton of Zurich (License 182/2011). Animal proce- dures were executed in accordance with Swiss law, with strict consideration given to the care and use of animals.

\section{Animals}

Transgenic mice expressing the conditional cre recombinase (i.e., CreERT2) under control of the human GFAP promoter (i.e., hGFAP; Hirrlinger et al., 2006) were crossed with the reporter mouse line ROSA26-Flox-Stop-Flox YFP (Jackson Laboratories) under standard conditions. A total of 64 mice (males and females) of $2-5$ months of age were used in this study. Recombination was induced by two daily intraperitoneal (i.p.) injections of $25 \mathrm{mM}$ Tamoxifen (Sigma, CH) dissolved in Corn Oil (Sigma, CH) $10 \%$ $\mathrm{EtOH}$, for 5 consecutive days.

\section{Spinal Cord Injury, EdU Labeling, and Tissue Processing}

SC injuries were performed under deep anesthesia (Hypnorm: fentanyl-citrate $0.7 \mathrm{mg} / \mathrm{kg}$, fluanison $22.5 \mathrm{mg} / \mathrm{kg}$, Janssen Pharmaceutics; Dormicum: midazolamum $22.5 \mathrm{mg} / \mathrm{kg}$, Roche Pharmaceutics, CH). A dorsal laminectomy was performed at T8 spinal level, and a dorsal compression injury was administered by delivering a constant force of $2 \mathrm{cN}$ for $2 \mathrm{~s}$ onto the exposed spinal cord. Immediately following injury, muscles were sewed and the skin stitched. Animals were allowed to recover for 4 days during which analgesic (Rimadyl, Pfizer, $5 \mathrm{mg} / \mathrm{kg}$ ) and antibiotics (Baytril, Bayer, DE $5 \mathrm{mg} /$ $\mathrm{kg}$ ) were administered. Bladder was manually emptied twice daily.

To label mitotic cells, two daily doses of $50 \mathrm{mg} / \mathrm{kg}$ EdU (Invitrogen) were administered i.p. to 2-month-old animals, in the 3 days following the injury. Non-injured animals were subjected to a similar protocol of EdU administration. Mice were sacrificed $2 \mathrm{~h}$ following the last EdU injection, i.e., at 4 days post-injury (d.p.i.), by terminal euthanasia with pentobarbital. Tissues were fixed through intracardial perfusion with Ringer's solution (Fresenius Kabi, DE) supplemented with $40 \mathrm{mM} \mathrm{NaNO}, 2 \mathrm{mM} \mathrm{NaCHO}$, and $50 \mathrm{IE} / \mathrm{mL}$ Heparin, followed by $4 \%$ paraformaldehyde in $0.1 \mathrm{M}$ phosphate buffer (PB). Tissues were cryoprotected by immersion in PB 30\% sucrose for 2 days before being cut into $40 \mu \mathrm{m}$ coronal or sagittal sections using a cryostat (Microm HM560, www.microm.de).

\section{Immunostaining Procedure}

Immunohistochemistry was performed on free-floating sections. For immunodetection of nuclear antigens, tissues were treated for $45 \mathrm{~min}$ in citrate buffer $\left(\mathrm{pH} \mathrm{6)}\right.$ at $80^{\circ} \mathrm{C}$. Following permeabilization and blocking in $0.1 M$ PB supplemented with $0.4 \%$ Triton-X (i.e., PBTx) and $10 \%$ heat-inactivated horse serum (HS), the sections were incubated with the primary antibodies for $12-36 \mathrm{~h}$ at $4^{\circ} \mathrm{C}$ in PBTx, $2 \%$ HS. Incubation with secondary antibodies was performed for $2-4 \mathrm{~h}$ at $4^{\circ} \mathrm{C}$ in PBTx, 2\% HS. When biotin-conjugated secondary antibodies were used, sections were subsequently incubated with fluorescent Alexa-conjugated streptavidin (Jackson ImmunoResearch, USA), 1:500 in $0.1 M$ PBTx for $10^{\prime}$ at room temperature. Nuclear counterstaining was achieved with DAPI $(0.5 \mu \mathrm{g} / \mathrm{mL})$ or TOPRO-3 $(0.05 \mu \mathrm{M}$, Invitrogen). Fluorescent detection of EdU-labeled cells was performed using the Click-it EdU Alexa Fluor 555 kit (Invitrogen) following manufacturer's guidelines. Primary antibodies used in the study were: 
rabbit anti-GFAP (1:500, DAKO, DE), mouse anti-GFAP (1:500, Millipore), mouse anti-NeuN (1:500, Millipore), mouse anti-CC1 (1:400, Calbiochem), mouse anti-Map2 (1:500, Sigma-Aldrich, CH), chicken anti-GFP (1:1000, Abcam, UK), mouse anti-RIP (1:200, Developmental Studies Hybridoma Bank), mouse anti-Mash1 (1:100, BD Pharmaceutics), rabbit anti-ID1 (1:500, Biocheck), goat anti-DCX (1:500, Santa Cruz) mouse anti-Nestin (1:400, BD Pharmaceutics), chicken anti-Vimentin (1:1000, Millipore), rabbit anti-Olig2 (1:500, Millipore), rabbit anti-BLBP (1:300, Abcam, UK), mouse anti$\beta$ catenin (1:500, BD Pharmaceutics), rabbit anti-Sox2 (1:200, Abcam, $\mathrm{UK})$, and rabbit anti-Connexin-30 (Cx-30, 1:500, Invitrogen). Speciesmatching secondary Alexa-conjugated (Invitrogen) or biotin-conjugated (Jackson Immunoresearch) antibodies raised in donkey were used at 1:1000 dilution. Immunostainings on cultured cells were performed as described above, whereas incubation times and dilutions of primary and secondary antibodies were halved. Following the staining procedure, sections were mounted on gelatin-coated slides. Both histological samples and cultures were coverslipped with anti-fading mounting medium Vectashield (Vector Lab).

\section{Neurospheres Cultures}

Progenitor cells were isolated from the SVZ of adult GFAPCreRT2 mice 7 days following induction of recombination. The SVZ was carefully microdissected from the rostral ventricular opening to the appearance of the fimbria. Alternatively, the whole SC was extracted (11 days post-recombination, i.e., 4 days following injury), and the meninges carefully removed to avoid contamination from other neurospheres-generating cell populations (Decimo et al., 2011). Tissues were digested with a solution of DNAse I (Worthington), Papain (Worthington), and Dispase II (Roche, $\mathrm{CH}$ ), subsequently triturated with fire-polished glass Pasteur pipettes of decreasing diameters. Single cells suspensions were filtered through a $70 \mu \mathrm{m}$ cell strainer (BD Falcon); for SC cultures, myelin debris was removed via continuous gradient centrifugation in $0.5 \times \mathrm{HBSS} / 30 \%$ sucrose. About $20 \times 10^{3}$ viable cells (i.e., 10 cells $/ \mu \mathrm{L}$ ) were plated into $2 \mathrm{~mL}$ of DMEM/F12 medium supplemented with N2 (Gibco), EGF, FGF2 (both $20 \mathrm{ng}$ / $\mathrm{mL}$, Peprotech), heparin $(1 \mu \mathrm{g} / \mathrm{mL})$, and antibiotic/antimycotic, in 2 $\mathrm{cm}$ Petri dishes. Primary spheres appeared in culture after 7-14 days in vitro (d.i.v.), and were then passaged after mechanical trituration. Subsequent passages were performed after 4-7 d.i.v., when the diameter of the majority of the neurospheres reached $50 \mu \mathrm{m}$. For differentiation studies, neurospheres were selected manually and plated onto Polylysine/laminin treated dishes and cultured in Neurobasal A supplemented with B27 (Gibco), Glutamax $0.5 \mathrm{mM}$, and antibiotics/antimycotic. All culture media were refreshed every second day. Cells were fixed with $4 \%$ paraformaldehyde after 3 or 14 d.i.v.

\section{Microscopy and Analysis}

IMMUNOGOLD STAINING AND TRANSMISSION ELECTRON MICROSCOPY. Mice $(n=2)$ were perfused with $0.9 \%$ saline, followed by $4 \%$ paraformaldehyde (PFA) and $0.5 \%$ glutaraldehyde (EMS, Hatfield, PA). Spinal cords were post-fixed overnight in $4 \%$ PFA then microdissected and $50 \mu \mathrm{m}$ spinal cord sections were cut on a vibratome (Leica). Pre-embedding immunogold stain- ing was performed by incubating sections in chicken anti-GFP primary antibody (1:200, Aves Lab) and in the appropriate colloidal gold-conjugated secondary antibody (1:50; UltraSmall; Aurion, Wageningen, The Netherlands). The samples were post-fixed in $1 \%$ osmium and $7 \%$ glucose for $30 \mathrm{~min}$, rinsed, dehydrated, and embedded in araldite (Durcupan; Fluka, Buchs, Switzerland). To identify the $\mathrm{YFP}^{+}$cells contacting the central canal lumen, semithin sections $(1.5 \mu \mathrm{m})$ were cut with a diamond knife and stained with toluidine blue. For the ultrastructural characterization of $\mathrm{YFP}^{+}$cells, 40-60 serial ultrathin sections $(60-70 \mathrm{~nm})$ of each $\mathrm{YFP}^{+}$cell $(n=$ 6) were cut with a diamond knife, stained with lead citrate, and examined under a transmission electron microscope (Tecnai Spirit G2; FEI, Eindhoven, The Netherlands) by using a digital camera (Morada, Soft Imaging System; Olympus, Tokyo, Japan). We photographed every section for cilia reconstructions. Adjustment of brightness and contrast of the pictures, if needed, was performed with Adobe Photoshop (Adobe Systems, San Jose, CA).

IMAGE ANALYSIS. For quantitative analysis of immunohistochemistry, the forebrain was subdivided in the following subregions: SVZ (from bregma -0.1 to +1.18 ), the rostral migratory stream (RMS; from bregma +1.98 to +2.96 ), and the olfactory bulb (OB; from bregma +3.08 to +4.28 ). Spinal cords were divided in the three subregions (i.e., cervical, thoracic and lumbar enlargements). The SC injured tissue was analyzed on $40 \mu \mathrm{m}$ coronal sections spanning \pm 2 $\mathrm{mm}$ from the lesion core. For the three regions studied (i.e., forebrain, SC, and SCI), analysis was performed on series of $40 \mu \mathrm{m}$ thick cross sections spaced $200 \mu \mathrm{m}$ from each other. Immunostainings were analyzed on confocal stacks (step size of $1 \mu \mathrm{m}$ ) acquired with laser scanning microscopes (SPE II, Leica, DE www.leica-microsystems.com; FV1000, Olympus, JP, www.olympusmicro.com). Presence of $\mathrm{YFP}^{+}$ spheres in culture was analyzed by a binocular microscope (Leica MZFLIII) equipped with YFP-specific filter cube $(\lambda 527 \mathrm{~nm})$. At least 50 neurospheres showing a diameter of $\geq 40 \mu \mathrm{m}$ were counted in each experiment. Neurospheres showing heterogeneous YFP expression (as described in Coles-Takabe et al., 2008, see also spheres indicated with a \# in Supp. Info. Fig. 2D) were not included in the quantifications. Only $\mathrm{YFP}^{+}$spheres showing full recombination (indicated with an arrow in Supp. Info. Fig. 2D) were counted as positive. Recombined and non-recombined spheres with a diameter $<40 \mu \mathrm{m}$ were not included in our quantifications (Supp. Info. Fig. 2D, two $\mathrm{YFP}^{+}$ small neurospheres are indicated with an asterisk). Images were analyzed with the ImageJ, LASAF (Leica) and Imaris (Bitplane, www.bitplane.com) softwares; final figures were assembled with Adobe Photoshop CS5 software. Statistical analysis was performed by unpaired $t$-test or Two-ways ANOVA (Prism; GraphPad). All quantifications are presented as mean \pm SEM. $N$ refers to the number of animals or independent in vitro experiments used for the quantifications.

\section{Results GFAPCreERT2 Mice Allow Successful Fate Mapping of SVZ NSCS}

NSCs of the adult SVZ express the glial intermediate filament protein GFAP (Doetsch et al., 1999; Ganat et al., 2006; Garcia et al., 2004). We confirmed the reliability of 
Fiorelli et al.: GFAP ${ }^{+}$Progenitors of the Adult Spinal Cord
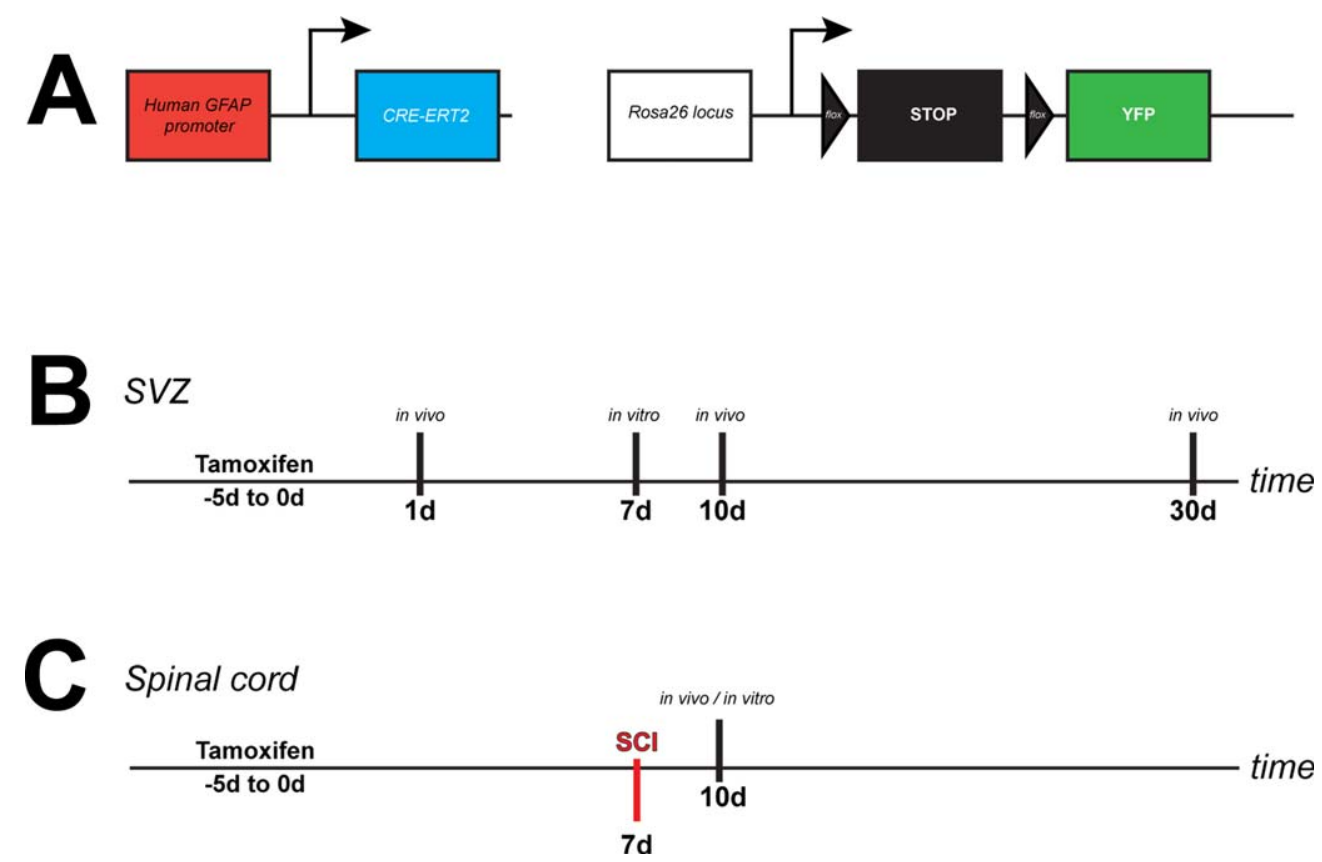

FIGURE 1: Schematic illustration of transgenic line and labeling paradigms. (A) Mice expressing a tamoxifen (Tam)-inducible Cre recombinase (i.e., CreERT2) under the control of the human GFAP (hGFAP) promoter were crossed with the reporter line Rosa26-flox-stop-floxYFP. (B) Recombination was induced by a regime of 5 days of Tam injections. Animals were sacrificed at 1, 10, and 30 days after the last Tam injection for histological analysis of the recombined cells in the forebrain. Neurospheres were derived from animals sacrificed 7 days "post-Tam treatment." (C) For analysis of the recombined cells in the spinal cord, animals received a spinal cord injury (or a sham operation) 7 days post-Tam treatment and were sacrificed 3 days later, for histology or preparation of neurospheres cultures. [Color figure can be viewed in the online issue, which is available at wileyonlinelibrary.com.]

the hGFAPCreRT2 mouse line with previously reported observations by analyzing the forebrain of this mouse line at different time points (i.e., 1,10 , and 30 days) following tamoxifen administration. The transgenic line, time points and labeling paradigms are depicted in Fig. 1. Successful recombination was already evident 1 day following tamoxifen treatment, in the parenchyma around the ventricles as well as in the SVZ (Fig. 2A). Confocal analysis confirmed GFAP expression by all recombined parenchymal $\mathrm{YFP}^{+}$astrocytes as well as by SVZ $\mathrm{YFP}^{+}$cells exhibiting a radial morphology (Fig. 2B). Importantly, at this early time point no $\mathrm{YFP}^{+}$ expression was detected in type-C (i.e., progenitors) and typeA (i.e., committed neuroblasts) SVZ cells, labeled with Mash1 and Dcx, respectively. We next assessed expression of the helix-loop-helix transcription factor ID1, a previously described marker of type-B1 SVZ (Azim et al., 2012; Nam and Benezra, 2009). As many as $43.8 \% \pm 2.3 \%$ (mean \pm SEM, $N=3$, cells: 120; Fig. 2C) SVZ YFP ${ }^{+}$cells expressed ID1, suggesting the presence of a large number of NSCs among the population of recombined SVZ astrocytes. Conversely, $31.4 \% \pm 11.8 \%,(N=3$, cells: 40$)$ of the $\mathrm{ID} 1^{+}$cells expressed YFP at this early time point, suggesting that about one third of SVZ-NSCs had successfully recombined.

Fate mapping analysis of the recombined cells was performed 10 and 30 days following recombination. At 10 days post-tamoxifen treatment, the lateral and dorsal walls of the SVZ (Fig. 2D), as well as the dorsolateral RMS and olfactory peduncle (Fig. 2I), were densely populated by $\mathrm{YFP}^{+}$cells, suggesting an enlargement of the pool of the recombined cells by proliferation. At this time point, the majority of recombined cells were positive for GFAP (79.3 $\pm 3.3 \%, N=3$, cells: 453; Fig. 2B), Nestin (71.7 $\pm 8.9 \%, N=3$, cells: 399; Fig. $2 \mathrm{E})$, Vimentin (71.5 \pm $2.1 \%, N=3$, cells: 404; Fig. $2 \mathrm{~F}$ ), and the radial glial marker BLBP (Fig. 2G), supporting their Type-B cell (i.e., NSCs) identity. The remaining $\mathrm{YFP}^{+}$cells comprised a mixed population of Type-C (Mash1 ${ }^{+}$, Fig. 2H) and Type-A cells (DCX ${ }^{+}$, Fig. 2I). The proportion of recombined type-C cells remained stable over time, representing $37.6 \pm 5.3 \%(N=3$, cells: 735$)$ and $35.6 \pm$ $0.6 \%(N=3$, cells: 342$)$ of all Mash $1^{+}$cells at 10 - and 30-day post-tamoxifen treatment. Recombined $\mathrm{DCX}^{+}$neuroblasts invading the olfactory bulb $(\mathrm{OB})$ were observed at 10 days while mature $\mathrm{NeuN}^{+}$recombined neurons were only observed in the OB granular layer 30 days post-tamoxifen treatment (Fig. 2L).

Altogether, these results indicate successful recombination in approximately one third of the neurogenic type B1 cells in the adult SVZ. These cells showed the hallmark characteristics of aSVZ-NSCs, i.e., self-renewal as illustrated by the stable number of type- $\mathrm{C}$ cells observed at 10 and 30 days, as well as neurogenic potential shown by the sequential acquisition of the neuronal markers DCX and NeuN. 

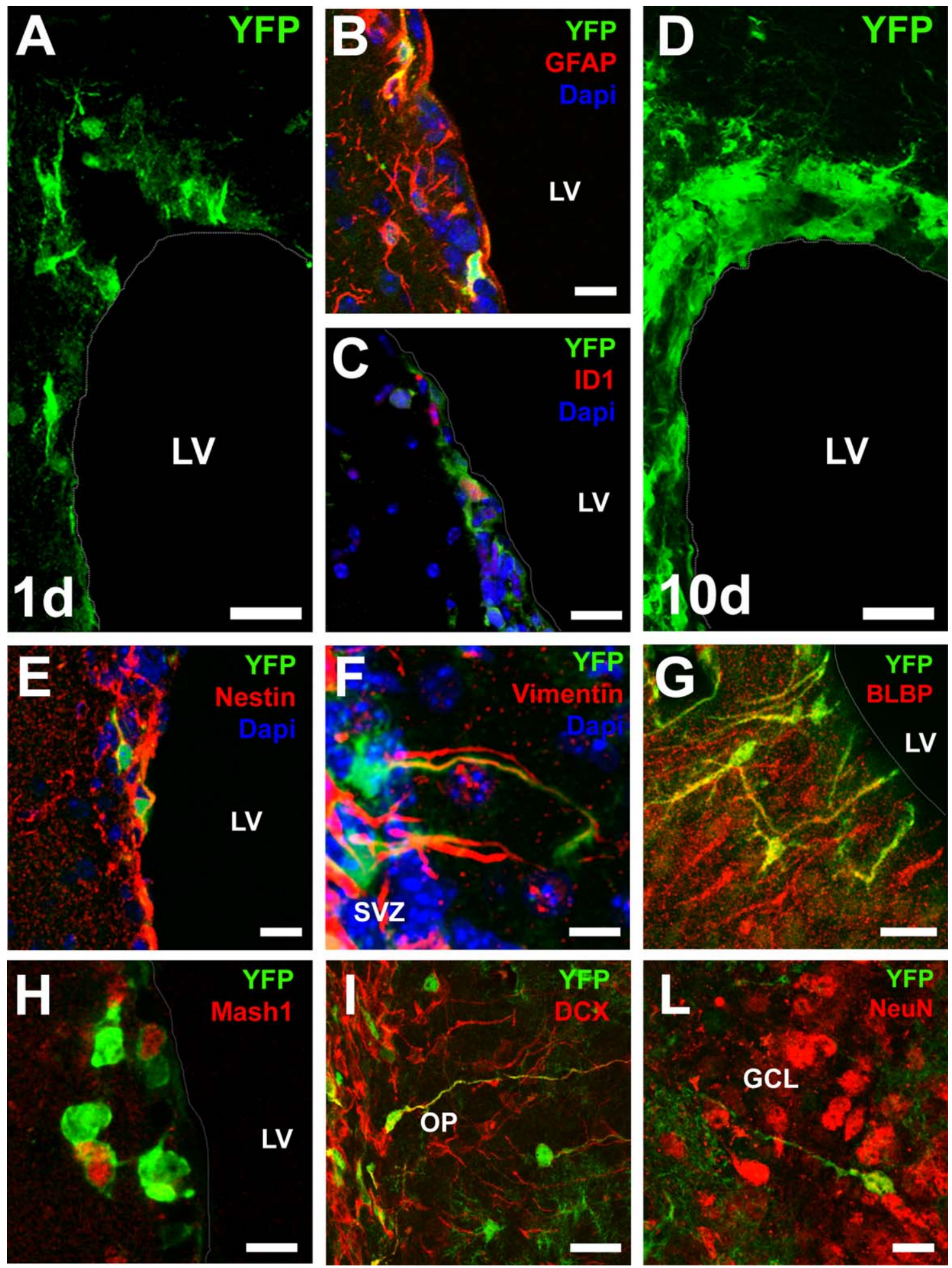

FIGURE 2: Fate mapping of GFAP-expressing neural stem cells in the adult forebrain. (A-C) One day after the last Tamoxifen (Tam) injection, a population of cells surrounding the lateral ventricle showed successful recombination. All the recombined cells expressed GFAP, confirming the reliability of the hGFAP-CreERT2 model (B). Based on the expression of the marker ID1 (C), we estimated that around $30 \%$ of recombined cells were NSCs (refer text for details). (D-G) Density of recombined cells greatly increased 10 days after recombination in the SVZ. Expression of the progenitor markers Nestin (E), Vimentin (F), and BLBP (G) was confirmed in a major population of recombined cells. $(\mathrm{H}, \mathrm{I})$ At 10 days post-Tam treatment, clusters of Mash1 ${ }^{+}$(i.e., type C) cells were observed in the SVZ $(\mathrm{H})$, as well as Dcx-expressing (i.e., type A) cells in the RMS and olfactory peduncle (I). (L) Neurons expressing the mature neuronal marker NeuN could only be observed in the granular layer of the olfactory bulb, 30 days after the induction of recombination. Scale bars: $20 \mu \mathrm{m}(\mathrm{A}, \mathrm{D}) ; 10$ $\mu \mathrm{m}(\mathrm{B}, \mathrm{C}, \mathrm{E}, \mathrm{G}, \mathrm{I}, \mathrm{L})$, and $5 \mu \mathrm{m}(\mathrm{H}, \mathrm{F})$. Abbreviations: LV, lateral ventricle; OP, olfactory peduncle; GCL, granule cell layer. [Color figure can be viewed in the online issue, which is available at wileyonlinelibrary.com.] 

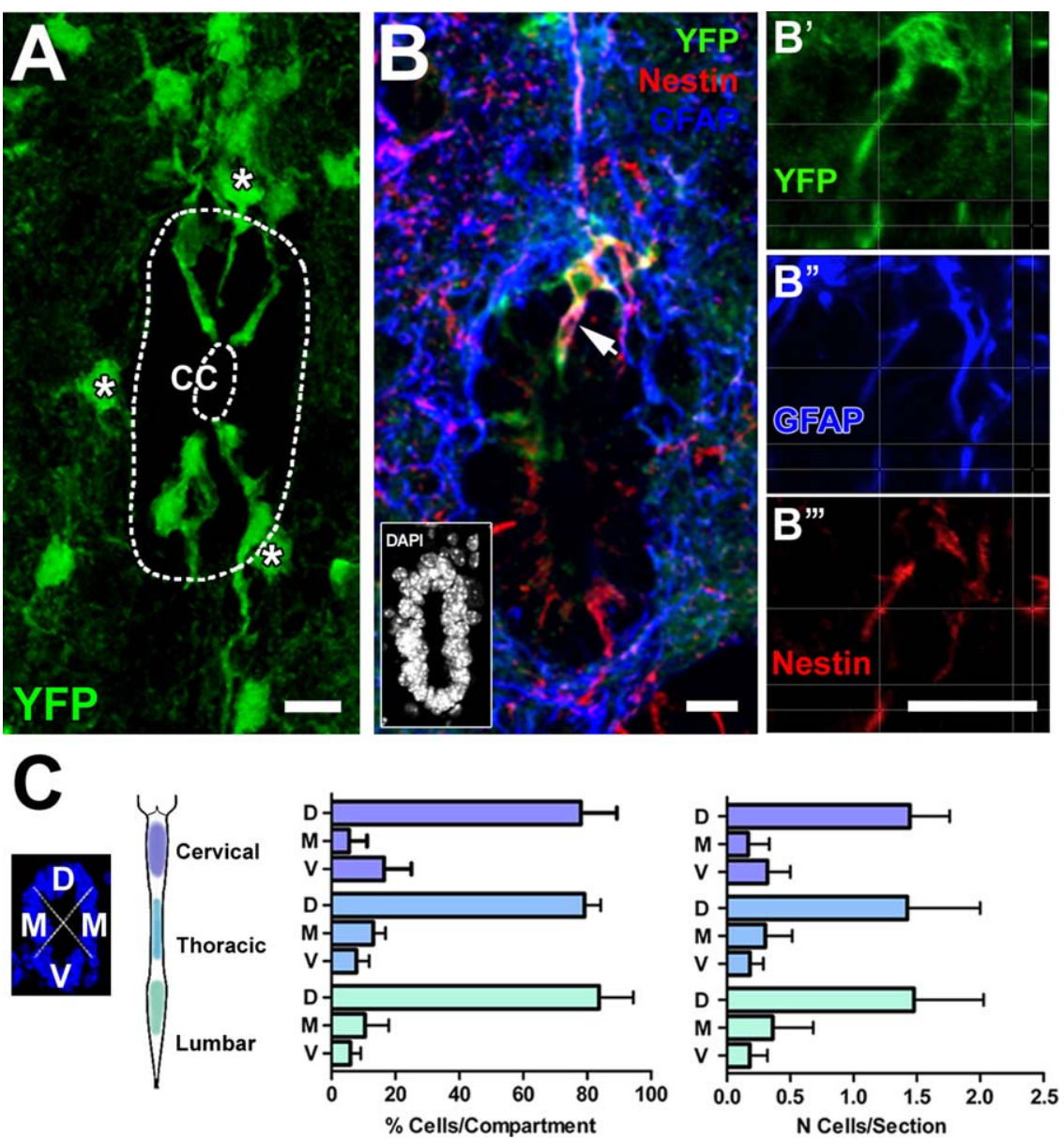

FIGURE 3: Fate mapping in the adult intact spinal cord reveal a population of periaqueductal GFAP expressing cells. (A) A population of recombined cells was observed close to the spinal cord central canal 10 days after tamoxifen treatment. Based on their GFAP immunoreactivity and typical morphology YFP ${ }^{+}$cells were identified as Acc (i.e., central canal-contacting astrocytes). Peri-ependymal astrocytes (indicated with the asterisks), were often observed but were not included in the analysis. (B) Recombined Acc expressed the progenitor marker Nestin, around the cell body and along the apical (arrow) and basal GFAP ${ }^{+}$processes. ( $\left.\mathbf{B}^{\prime}-\mathbf{B}^{\prime \prime \prime}\right)$ show a single plane image and 3D reconstruction of the cell in B. GFAP immunodetection showed weak expression in the soma, but stronger expression in the basal (data not shown) and apical ( $B^{\prime \prime}$ ) processes. (C) Quantification of recombined Acc throughout the spinal cord revealed that an average of $2 \pm 0.8$ cells were observed in $40 \mu \mathrm{m}$ thick coronal sections ( $N=3,172$ cells quantified in 85 sections) with no quantitative differences between the cervical, thoracic, and lumbar subregions of the spinal cord. Analysis of their distribution revealed that the vast majority (i.e., $80.2 \pm 7.4 \%, N=3$, cells: 172) of YFP ${ }^{+}$Acc resided in the dorsal pole of the CC. Scale bars: $10 \mu \mathrm{m}$. Abbreviations: GM, gray matter; WM, white matter; CC, central canal; D, dorsal; M, medial; V, ventral. [Color figure can be viewed in the online issue, which is available at wileyonlinelibrary.com.]

\section{GFAPCreERT2 Mice Allow Successful Fate Mapping of Spinal Cord Parenchymal and Central Canal- Contacting Astrocytes}

We next analyzed the pattern of recombination in the spinal cord of the GFAPCreERT2 mice at 10 days post-tamoxifen treatment. A large number of $\mathrm{YFP}^{+}$cells were homogeneously distributed throughout the white (WM) and grey (GM) matter, and were positive for GFAP (Supp. Info. Fig. 1A, B). In agreement with a previous report (Hirrlinger et al., 2006), recombination efficiency was higher in the SC compared with the forebrain, with $77.5 \% \pm 1.3 \%(N=3$, cells: 173$)$ of the WM fibrous astrocytes, and $81.9 \% \pm 2 \%(N=3$, cells: 654) of the GM population of protoplasmic astrocytes expressing YFP. Recombined cells were negative for the neu- ronal marker NeuN and only rarely expressed the oligodendroglial marker APC (<0.5\%; Supp. Info. Fig.1C,D). Thus, recombination occurred in a majority of parenchymal $\mathrm{GFAP}^{+}$ astrocytes, a population of cells that lack neurospheresforming capacities (Barnabe-Heider et al., 2010).

Interestingly, recombined cells were also observed around the central canal (CC; Fig. 3A), a region considered to be a niche for quiescent NSCs (Barnabe-Heider et al., 2010; Sabourin et al., 2009). In $40 \mu \mathrm{m}$ thick SC coronal sections, between 1 and 4 recombined cells per section were found in the ependymal layer (Fig. 3A). Sub-ependymal astrocytes, located immediately below ependymal cells, were also common (Fig. 3A, indicated with a star), but were not included in our analysis. GFAP-expressing cells residing in 


\section{GLLA}
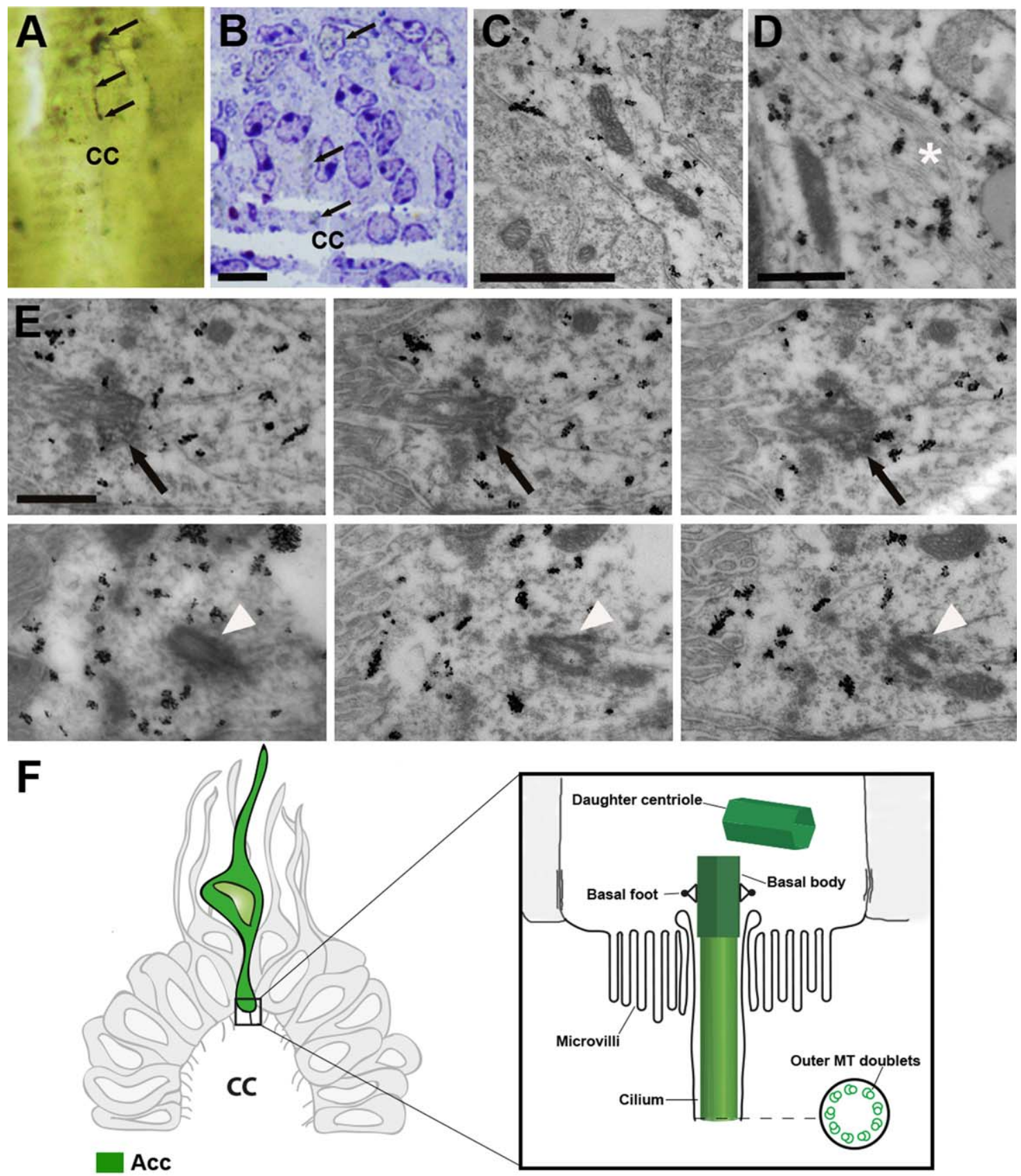

\section{Ependymal cells}

FIGURE 4: Pre-embedding immunogold detection of YFP. (A) Flat Durcupan embedded section showing immunogold-labeled YFP $^{+}$cell (arrows). (B) Toluidine blue-stained semithin section showing gray immunogold-silver labeling for YFP in one cell and its thin expansion in contact with the central canal lumen. (C,D) TEM details of the immunogold-labeled cell thin expansion showing typical characteristics of Acc: light cytoplasm and intermediate filaments (asterisk). (E) TEM serial sectioning of the labeled cell displaying a typical single cilium basal body (arrow) with an orthogonally oriented centriole (arrowhead). (F) Schematic representation of a typical dorsal Acc cell with detailed structural organization of the cilium. The core structure of Acc cilia is composed of nine outer microtubule doublets $(9+0$ configuration) extending from the basal body. The basal body, which is a modified mother centriole, is associated with a perpendicular daughter centriole. The ciliary membrane is continuous with the plasma membrane. Scale bar: $10 \mu \mathrm{m}$ (B); $1 \mu \mathrm{m}$ (C); $500 \mathrm{~nm}$ (D-E). [Color figure can be viewed in the online issue, which is available at wileyonlinelibrary.com.]

the SC ependymal cell layer have recently been defined as CC-contacting astrocytes (Acc; Alfaro-Cervello et al., 2012), a nomenclature that we used thereafter. Recombined Acc indeed showed a radial bipolar morphology, with an apical process contacting the lumen of the $\mathrm{CC}$ and a basal process running medially along the SC groves. These $\mathrm{YFP}^{+}$cells strongly expressed GFAP along both their basal and more weakly in their apical processes (Fig. 3B, arrowheads). In 
addition, they expressed the progenitor markers Nestin (Fig. $3 \mathrm{~B}$ ) and Vimentin (data not shown), as well as Sox 2 and $\beta$ catenin (Supp. Info. Fig. 1E, G) but not the SVZ-NSC markers Id1 and BLBP (data not shown). Furthermore, Acc were negative for the tight junction protein connexin-30 (Supp. Info. Fig. 1F) which was strongly expressed in periependymal (Supp. Info. Fig. $1 \mathrm{H}$ ) and parenchymal astrocytes (data not shown). Thus, both morphological and marker expression, distinguish Acc from parenchymal astrocytes and suggest that Acc might retain NSC characteristics.

On average, we found $2 \pm 0.8$ Acc/section $(N=3$, 172 cells quantified in 85 sections) throughout the rostrocaudal SC extent (Fig. 3C). Quantification of Acc in three arbitrarily defined CC subregions (dorsal, medial, and ventral; Fig. 3C, inset) showed that the vast majority of $\mathrm{YFP}^{+} \mathrm{Acc}$ were found in the dorsal-most region of the CC (80.2 \pm $7.4 \%, N=3$, cells: 172 ), with the remaining cells distributed evenly between medial zone and ventral pole (respectively, 9.6 $\pm 5.4 \%$ and $10 \pm 2.1 \%, N=3$ ). This distribution of $\mathrm{YFP}^{+}$ Acc was conserved along the cervical, thoracic and lumbar regions of the SC (Fig. 3C).

By using electron microscopy in combination with YFP immunogold staining, we confirmed the astroglial identity of $\mathrm{YPF}^{+}$cells contacting the CC lumen (Acc; Fig. 4A,B). These cells had light cytoplasm, nuclei with irregular borders and thick bundles of intermediate filaments homogeneously distributed within the cytoplasm, in contrast to the clumped organization of ependymal cells intermediate filaments (Fig. 4C,D). In addition, labelled cells contacted the central canal through a thin process and had a single cilium and associated daughter centriole (Fig. 4E). Interestingly, one of the 5 threedimensional reconstructed cells showed a single cilium with a large and electron dense basal body, resembling the biciliated Ecc basal bodies.

\section{SVZ and Spinal Cord Neurospheres Derived from GFAP $^{+}$Progenitors Differ in their Frequency and Self-Renewing Capabilities}

NSCs identity is classically assessed in vitro, by performing neurosphere assays (Brewer and Torricelli, 2007). In order to assess the contribution of SVZ and spinal cord GFAPexpressing cells to neurosphere formation, we derived neurospheres cultures from these two regions, 10 days posttamoxifen treatment. Primary neurospheres (P0; Fig. 5A) appeared between 7-14 d.i.v. in the two samples. When the SVZ-derived cultures were examined under an epifluorescent binocular microscope, $35.8 \pm 2.4 \%(N=4$, spheres: 192$)$ of the neurospheres showed full recombination indicating their clonal origin from GFAP-expressing cells. In contrast, only $16.8 \pm 0.5 \%(N=3$, spheres $=124 ; P=0.0025, t$-test; Fig. $5 \mathrm{~B}$ ) of the spinal cord primary neurospheres showed YFP expression. Notably, while the proportion of recombined neurospheres remained stable over several passages in the SVZderived cultures $(t$-test, $P>0.5)$, it rapidly decreased in SCderived cultures (P0 to P1, t-test: $P<0.001$; $\mathrm{P} 1$ to $\mathrm{P} 2$, t-test: $P<0.05$ ) to fully disappear at passage 4 (Fig. 5B,C). Recombined spinal cord and SVZ-derived P1 neurospheres showed comparable multipotency (Fig. 5D,E). Upon differentiation, recombined SC-neurospheres gave rise to $47.5 \pm$ $7.2 \% \mathrm{Map}^{+}$neurons and $38 \pm 8.4 \% \mathrm{GFAP}^{+}$astrocytes $(N$ $=3$, cells $=728$; Fig. 5E). Similarly, recombined SVZneurospheres gave rise to $57.9 \pm 0.5 \%$ neurons and $32.8 \pm$ $0.9 \%$ astrocytes $(N=3$, cells: 1100 ; Fig. $5 \mathrm{E})$. In all cultures, rare $\mathrm{RIP}^{+}$oligodendrocytes were obtained from $\mathrm{YFP}^{+}$cells following 2 weeks of differentiation (data not shown). Thus, $\mathrm{GFAP}^{+}$cells of the adult spinal cord retain multipotentiality but have a limited capacity for self-renewal when compared with SVZ-GFAP ${ }^{+}$cells.

\section{Spinal Cord Injury Increases GFAP ${ }^{+}$Cells Proliferation Near the Central Canal}

To characterize the response of recombined $\mathrm{GFAP}^{+}$cells to spinal cord injury (SCI), we performed a thoracic (Th8) compression injury. In order to prevent recombination in cells that would up-regulate GFAP following injury, GFAPCreRT2 mice were injured 7 days following the last tamoxifen injection, a delay sufficient for full clearance of the drug. Administration of EdU over a 3-day period (starting at 1 d.p.i.) revealed a dramatic increase in the number of proliferating cells following injury (compare Fig. 6A,B), in agreement with previous studies (Zai and Wrathall, 2005). In the parenchyma surrounding the CC, the density of EdU-incorporating cells increased from $1.4 \times 10^{3} \pm 0.1 \times 10^{3}$ cells $/ \mathrm{mm}^{3}$ (in intact conditions; $N=3$, cells: 133 ) to $69.7 \times 10^{3} \pm 2.2 \times 10^{3}$ cells $/ \mathrm{mm}^{3}$ (i.e., 50-fold increase, t-test: $P<0.005, N=3$; cells: 3906; Fig. 6C). As previously described, parenchymal astrocytes represented a significant proportion of these proliferating cells (i.e., $14 \pm 4 \%, N=3$; cells: 898; $P<0.05$ compared with intact tissue, $t$-test; Fig. 6D).

Analysis of the ependymal cell layer in proximity to the site of injury revealed a similar marked increase in the EdUlabeled cells when compared with the intact SC $(45 \pm 2.1$ cells/section vs. $1.8 \pm 0.5$ cells/section, respectively; i.e., a 25-fold increase, $t$-test: $P<0.005, N=3$ per group, cells: intact 59, injury 897, Fig. 6E). In agreement with their low density, recombined Acc represented only $2.5 \pm 1.2 \%$ of all the EdU labeled cells in the CC ependymal cell layer in the intact spinal cord ( $N=3$, sections: 85 , cells: 179). Following injury, they however profoundly enhanced their proliferation (10.3 $\pm 3.7 \mathrm{YFP}^{+} / \mathrm{EdU}^{+}$cells/section, $N=3$, cells: 209$)$, representing $23.8 \pm 9.7 \%$ of the $\mathrm{EdU}^{+} \mathrm{CC}$ cells $(N=3$, ttest: $P<0.05$; Fig. 6F). In agreement with results obtained 

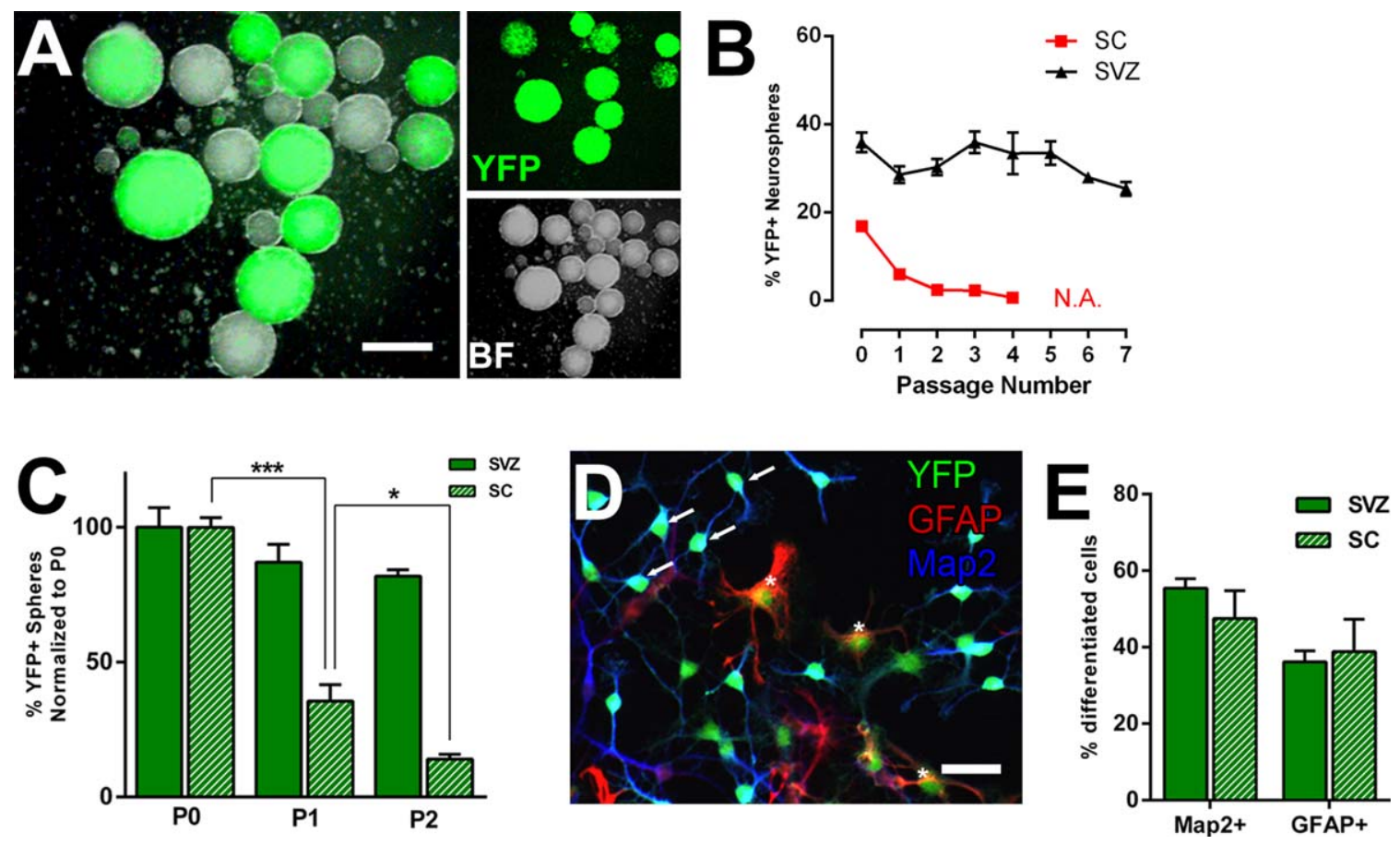

FIGURE 5: Neurospheres-forming potential of SVZ and spinal cord-derived recombined cells. (A) Numerous clonal YFP ${ }^{+}$spheres were $^{+}$ observed in cultures prepared from the adult SVZ (data not shown) or spinal cord (A). (B,C) Quantification of the number of YFP ${ }^{+}$neurospheres revealed that $35.8 \pm 2.2 \%(N=4$, spheres $=192)$ of the primary SVZ spheres were recombined, demonstrating that they derived from GFAP-expressing cells. The \% of recombined spheres in these cultures did not show major changes over several passages ( $B$, black line). In contrast, $16.8 \pm 0.5 \%(N=3$, spheres $=124)$ of spinal cord-derived primary neurospheres showed recombination. SCderived $\mathrm{YFP}^{+}$neurospheres dramatically decreased over three passages (C), and were absent from passage 4 on (B, red line). The first three passages are analyzed in $\mathrm{C}$ where data are normalized for the $\%$ of $\mathrm{YFP}^{+}$spheres in the primary (i.e., P0) cultures. While the proportion of recombined neurospheres remained stable over several passages in the SVZ-derived cultures ( $t$-test, $P>0.5)$, it rapidly decreased in SC-derived cultures (P0 to P1, t-test: $P<0.001$; $P 1$ to $P 2$, $t$-test: $P<0.05 ;>100$ spheres counted for each passage in each condition) to fully disappear at passage 4 . ${ }^{\star} P<0.05 ;{ }^{* \star \star} P<0.0001$. (C-E) Despite marked differences in their self-renewal properties (C); both SVZ and SC-derived neurospheres were shown to be multipotent (D, E). Three days after mitotic factor removal, many YFP ${ }^{+}$ cells had differentiated into GFAP ${ }^{+}$astrocytes (red, asterisks) and Map2 ${ }^{+}$neurons (blue, arrows), as quantified in D. Scale bars: $50 \mu \mathrm{m}$ (A); and $20 \mu \mathrm{m}$ (C). Abbreviations: BF, bright field. [Color figure can be viewed in the online issue, which is available at wileyonlinelibrary.com.]

from the intact spinal cord (see above) only rare $\mathrm{EdU}^{+}$ recombined Acc were observed in SC regions distant from the injury site (i.e., the spared cervical and lumbar enlargements). These results confirm that the proliferation of CC cells is locally increased by the spinal cord injury (Meletis et al., 2008). Furthermore, they show that Acc represent a non-negligible proportion (i.e., $1 / 5$ th) of the total CC cells undergoing mitosis in response to SCI.

\section{SCI Promote the Self-Renewal Properties of GFAP- Derived Spheres}

In order to investigate the effect of SCI on the multipotency and self-renewal properties of $\mathrm{GFAP}^{+}$cells, neurosphere cultures were derived from intact and injured SC (Fig. 7A). The proportion of primary $\mathrm{YFP}^{+}$neurospheres was comparable between the two cultures (Fig. 7B, $t$-test: $P>0.5$ ), indicating no recruitment of additional populations of $\mathrm{GFAP}^{+}$progenitors after SCI. In clear contrast, the self-renewal of the recombined spheres was greatly enhanced after injury (Fig. 7B;
Two-ways ANOVA: $P<0.0001, F=3.98$; intact $N=4$, injury $N=5$ ). The diameter of the spheres at $\mathrm{P} 0$ and $\mathrm{P} 1$ was not significantly different between experimental conditions (Fig. 7C). Multipotentiality was compared by plating secondary (P1) neurospheres and exposing them to differentiating conditions (Fig. 7D-F). Spheres from intact or injured spinal cord showed similar neuronal (i.e., $47.5 \pm 7.2 \%$ for intact and $48.5 \pm 6.6 \%$ for injured SC, $N=3,701$ cells analyzed), and astroglial differentiation (i.e., $38 \pm 8.4 \%$ and $33.4 \pm 4.1 \%)$, with rare oligodendrocytes being observed $(<0.2 \%$ of the cells; Fig. $7 \mathrm{~F})$. Non-recombined neurospheres produced a similar proportion of $\mathrm{Map}^{+}$neurons and $\mathrm{GFAP}^{+}$astrocytes in both conditions (intact-derived: $50.0 \pm$ $4.4 \%$ neurons and $36.4 \pm 1.2 \%$ astrocytes, $N=3$, cells $=$ 853; injured-derived: $46 \pm 2.4 \%$ neurons and $32.6 \pm 2.4 \%$ astrocytes, $N=3$, cells $=1139$ ). Altogether, these results indicate that SCI prolongs the proliferative capacities of GFAP-expressing multipotent progenitors in the adult spinal cord. 

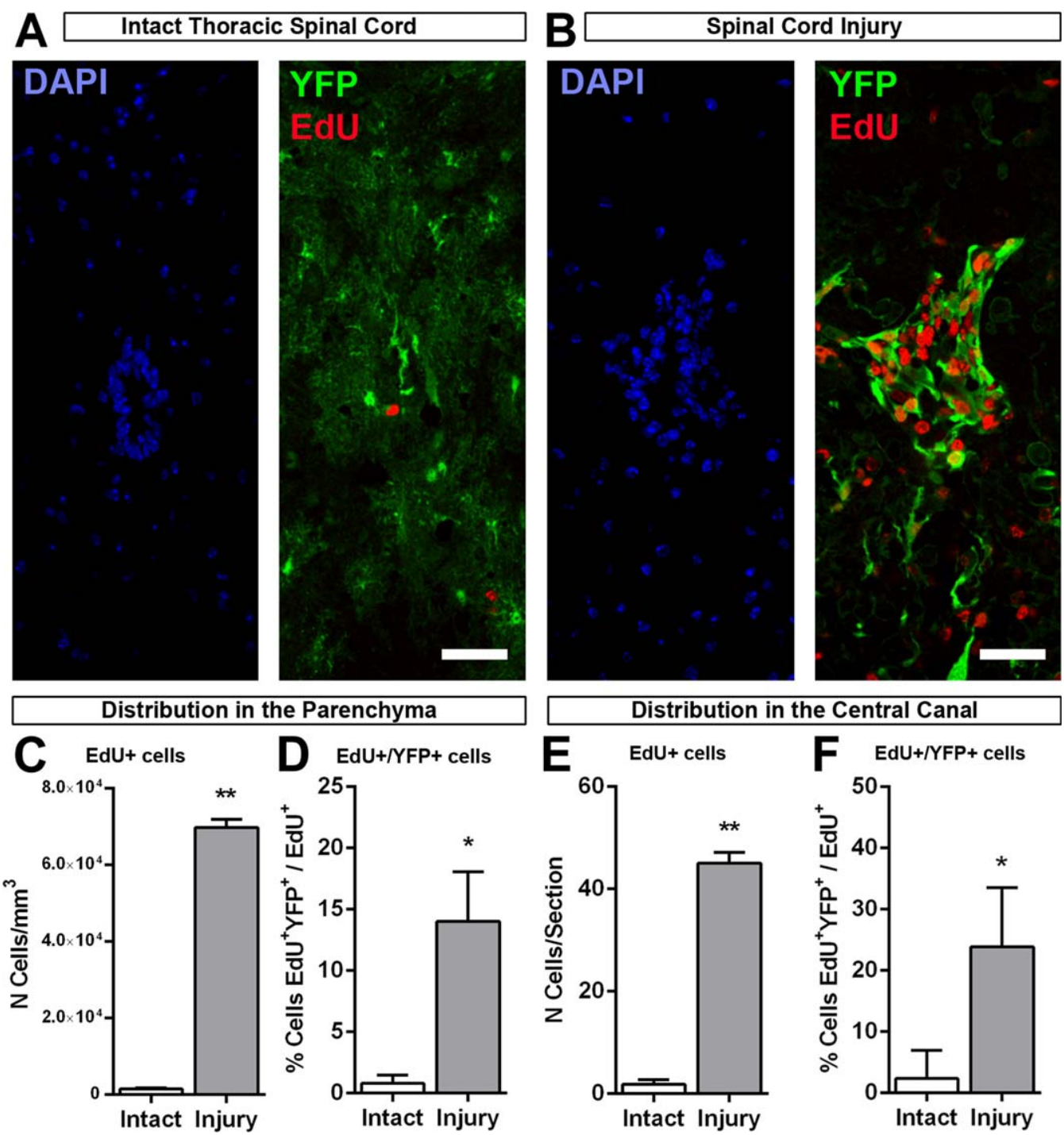

FIGURE 6: Spinal cord injury induces proliferation of GFAP+ cells: (A) After a 3-days treatment with the mitotic marker EdU only rare EdU-labeled cells were seen in the ependymal layer as well as in the parenchyma. (B) After injury, the number of EdU-positive cells greatly increased close to the injury site, both in the parenchyma and CC, where many proliferating cells were recombined. (C,D) Quantification of $\mathrm{EdU}^{+}$cells numbers in the parenchyma. Whereas proliferation was minimal in the intact parenchyma (white bars; $1.4 \times 10^{3} \pm$ $0.1 \times 10^{3}$ cells $/ \mathrm{mm}^{3} ; N=3$, cells: 133 ), injury resulted in a 50 -fold increase in the number of EdU ${ }^{+}$cells (gray bars; $69.7 \times 10^{3} \pm 2.2 \times$ $10^{3}$ cells $/ \mathrm{mm}^{3}$; t-test: $P<0.005, N=3$; cells: 3906 ). Only $2 \%$ of recombined astrocytes in the intact spinal cord incorporated EdU, while following injury the proportion of recombined $\mathrm{EdU}^{+}$cells increased to $14 \pm 4 \%(N=3$; cells: 898 ; $P<0.05$ compared with intact tissue, t-test). (E) Following injury, a similar increase in proliferation could be observed in the spared CC $\pm 2 \mathrm{~mm}$ from the injury core Here, EdU-labeled cells increased 25 fold compared with the intact situation $(45 \pm 2.1$ cells/section vs. $1.8 \pm 0.5$ cells/section, respectively; i.e., a 25-fold increase, t-test: $P<0.005, N=3$, cells: 897). (F) Acc represented a minor population of CC EdU-incorporating cells in intact situation $\left(2.5 \% \pm 1.2 \% \mathrm{YFP}^{+} \mathrm{EdU}^{+} / \mathrm{EdU}^{+}, \mathrm{N}=3\right.$, sections: 85 , cells: 179$)$. After injury, the proportion of recombined proliferating cells in the CC significantly increased to $23.8 \pm 9.7 \% \mathrm{YFP}^{+} \mathrm{EdU}^{+} / \mathrm{EdU}^{+}(N=3$, cells $=209$; $t$-test: $P<0.05)$, suggesting that Acc locally enlarge their numbers after spinal cord injury. ${ }^{*} P<0.05$; ${ }^{*}<0.005$; Scale bars: $30 \mu \mathrm{m}(A, B)$. [Color figure can be viewed in the online issue, which is available at wileyonlinelibrary.com.]

\section{Discussion}

Here, we used inducible transgenic mice to label and fate map populations of GFAP-expressing cells in the adult SC. We confirm the existence of a population of rarely dividing, CCcontacting astrocytes (Acc; Alfaro-Cervello et al., 2012), residing within the ependymal cell layer, i.e., the stem cell niche of the adult SC (Hugnot and Franzen, 2011). By systematically assess- ing their multipotent and self-renewal properties in vitro, we show that GFAP-expressing Acc are progenitors capable to generate clonal multipotent neurospheres. These cells however show limited self-renewal properties when compared with GFAP-expressing SVZ-NSCs. Spinal cord injury enhanced Acc proliferation in vivo, and prolonged the self-renewal properties of GFAP-derived neurospheres in vitro. Our findings reconcile 

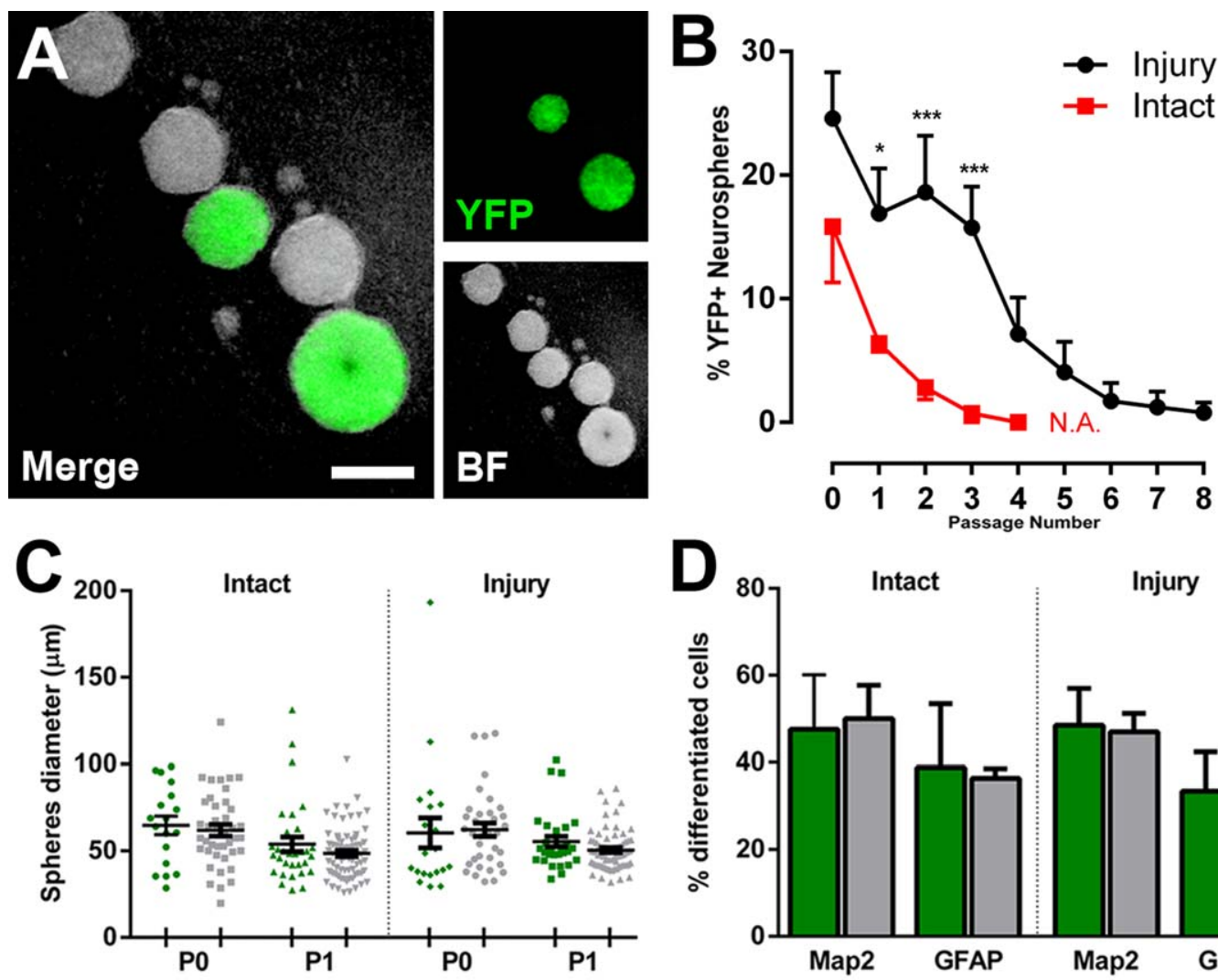

D
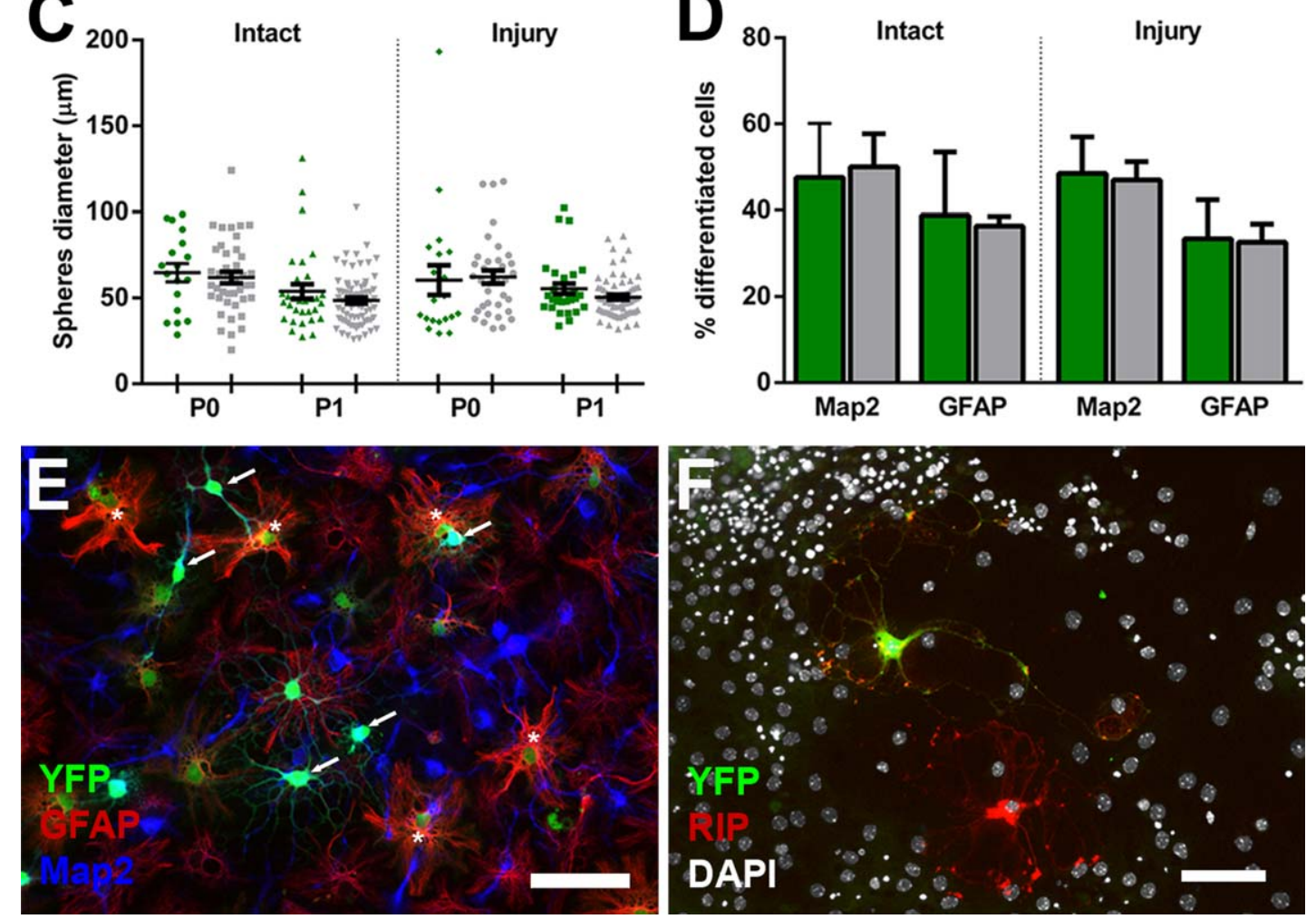

FIGURE 7: Spinal cord GFAP ${ }^{+}$progenitors increased self-renewal after injury. $(\mathbf{A}, \mathbf{B})$ Comparison of the number and self-renewal properties of recombined neurospheres isolated from the intact (black line) and injured (red line) spinal cord. Data represent repeated independent experiments (Intact: $N=4$; Injury: $N=5 ; 2$ mice used in each experiment). Whereas the proportions of primary recombined neurospheres were similar (Intact: $15.9 \pm 4.5 \%, N=4,152$ spheres counted; Injury: $21.1 \pm 4.5 \%, N=5,246$ spheres; $t$-test: $P>0.5$ ), injury greatly increased their self-renewal capacity (Two-ways ANOVA: significant culture $\times$ passage interaction, $P<0.0001, F=3.98$; asterisks in $B$ mark the passages with significant difference between intact- and injury-derived cultures based on post-hoc comparison using the error variance associated with the significant culture $X$ passage interaction. $\left.{ }^{*} P<0.05 ;{ }^{*} \star * P 0.0001\right)$. Despite a clear decrease in the number of recombined neurospheres over passages, $\mathrm{YFP}^{+}$neurospheres prepared form injury animals could still be observed after eight passages. (C) Diameters of the neurospheres were compared at P0 and P1. No significant differences were found between YFP ${ }^{+}$(i.e., Acc-derived) and negative (i.e., ependyma-derived) neurospheres. (D-F) Similarly, multipotency in a differentiation assay did not show significant differences between the two experimental conditions. The vast majority of cells differentiated in Map2 ${ }^{+}$neurons $\left(E\right.$, arrows) and $\mathrm{GFAP}^{+}$astrocytes $(\mathrm{E}$, asterisks) while rare RIP $^{+}$oligodendrocytes were observed after 2 weeks in culture (F). Scale bars: $50 \mu \mathrm{m}(\mathrm{A})$; and $20 \mu \mathrm{m}(\mathrm{E})$. Abbreviations: BF, bright field. [Color figure can be viewed in the online issue, which is available at wileyonlinelibrary.com.]

divergent views on the identity of SC-NSCs (Hugnot and Franzen, 2011; Sabelstrom et al., 2013) by showing that cells from both GFAP-positive and -negative lineages are multipotent in the adult spinal cord. Our long-term fate mapping experiments however reveal that, in striking contrast to the aSVZ, GFAPpositive cells of the adult spinal cord show only limited selfrenewal even after injury. These observations identify them as multipotent progenitor cells. 
The transgenic model used here is based on the human GFAP promoter (hGFAP, Hirrlinger et al., 2006) controlling expression of an inducible Cre recombinase. This approach has been used in several studies to drive recombination in GFAP-expressing cells of the forebrain or spinal cord, either directly (hGFAP-GFP, Beckervordersandforth et al., 2010; Platel et al., 2009; Sabourin et al., 2009), or via Cre/Lox methods (hGFAP-Cre; Ganat et al., 2006; Malatesta et al., 2003). Our immunostainings using either polyclonal or monoclonal GFAP antibodies confirmed reliable hGFAP-driven transgene expression in a population of GFAP-expressing cells that is in close contact to the ventricular system in both the SVZ and SC. Based on the use of stem and progenitor cells markers (ID1 and Mash1, respectively; Nam and Benezra, 2009; Parras et al., 2004), we estimated that around $30 \%$ of the NSCs population recombined in the adult SVZ. In contrast to the SVZ, the recombination efficiency was superior to $80 \%$ in parenchymal $\mathrm{GFAP}^{+}$cells of the spinal cord, while accurate quantification in the CC region was rendered difficult due to the cytoplasmic expression of GFAP and the clustering of the positive cells. Whereas this region-dependent variability of the recombination efficiency (Hirrlinger et al., 2006; Malatesta et al., 2003) prevented a direct comparison of the frequency at which recombined cells contribute to neurosphere formation, it did not preclude comparison of the multipotential and long term self-renewal properties of GFAP-expressing cells derived from the SVZ and SC.

A neurosphere assay (Reynolds and Weiss, 1996) was used in combination with hGFAP-fate mapping to assess and compare the identity of cells with NSCs properties in the SVZ and in the SC. Previous studies showed that GFAPexpressing cells of the postnatal SVZ generate neurospheres when exposed to mitotic factors FGF2 and/or EGF in vitro, while juxtaposed ependymal cells fail to do so (Beckervordersandforth et al., 2010; Chiasson et al., 1999). Our results indeed showed that $30 \%$ of the multipotent SVZ neurospheres showed persistent YFP-expression when serially passaged, in agreement with our in vivo estimation of the rate of recombination occurring in this region (see above). Recent evidence suggests that this glial lineage of NSCs might not be preserved in the spinal cord (Barnabe-Heider et al., 2010; Obermair et al., 2010). In this region, neurospheres are known to derive from cells residing near the central canal and expressing the ubiquitous stem/progenitor marker Nestin, as well as FoxJ1, a transcription factor involved in cilia formation (Meletis et al., 2008; Ostrowski et al., 2003). Hence, ciliated ependymal cells would represent the main stem cell population of the SC, in contrast with the SVZ situation.

Our results confirm that neurospheres only form in SCderived cultures when the central canal is included. The presence of a small but non-negligible population of recombined neurospheres $(\sim 20 \%)$ in our SC-derived cultures however demonstrates the existence of a foreseen population of GFAPexpressing cells, with multipotent properties, in the adult SC. Thus, our results suggest that the CC ependymal cell layer is composed of at least two sub-populations of cells that can generate multipotent neurospheres. These two CC-contacting cell populations can be distinguished by their expression of GFAP (Alfaro-Cervello et al., 2012; Hamilton et al., 2009; Sabourin et al., 2009), with ependymal cells (Ecc) being

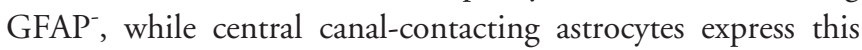
marker (Acc; Alfaro-Cervello et al., 2012). Visualization of these Acc by GFAP-driven transgenesis revealed that they are enriched in the dorsal aspect of the CC throughout the spinal cord. Our results show that they do not express connexin-30, a marker of parenchymal astrocytes that lack the capacity to produce neurospheres (Barnabe-Heider et al., 2010). In contrast, they show a high degree of phenotypic similarities to the Type B1 cells of the SVZ (Supp. Info. Table 1), most importantly expression of GFAP (Alfaro-Cervello et al., 2012; Mirzadeh et al., 2008) and Hes1 (Ohtsuka et al., 2006; Sabourin et al., 2009), the presence of one single apical cilium and the daughter centriole (Alfaro-Cervello et al., 2012; Mirzadeh et al., 2008; Wyszynski et al., 1997), and a long basal $\mathrm{GFAP}^{+}$process (Hamilton et al., 2009; Mirzadeh et al., 2008). Those features are also common to tanycytes (Hamilton et al., 2009; Mothe and Tator, 2005), a subpopulation of which (i.e., the $\alpha 2$-tanycytes) present neural progenitor properties in the dorsal regions of the third ventricle (Robins et al., 2013). Further studies are necessary to fully clarify similarities in between these three cell types.

A previous short-term fate mapping study using the hGFAP-GFP mouse line suggested that Acc may participate to neurosphere formation, although clonal analysis and longterm fate mapping were not performed (Sabourin et al., 2009). Our results confirm the capacity of those cells to form clonal multipotent primary spheres. However, the persistent expression of the reporter gene together with serial passaging demonstrates a rapid disappearance of the recombined neurospheres. Thus, unlike SVZ-NSCs, GFAP-expressing cells of the adult SC are multipotent progenitors that lack the longterm self-renewal potential of neural stem cells. These results highlight the heterogeneity of cell lineages showing NSCs properties in neurogenic and non-neurogenic regions of the adult CNS. Interestingly, the in vitro self-renewal properties appeared to be directly correlative with the in vivo proliferative behavior of the recombined cells. Our analysis indicates that proliferation is indeed very limited in the intact spinal cord CC. After spinal cord injury, a dramatic increase of Acc proliferation was paralleled by an increase in the self-renewal properties of recombined neurospheres in our in vitro assay. However, it should be noted that even after injury, the selfrenewal properties of GFAP-derived neurospheres isolated 
from the SC failed to match those of the SVZ, therefore confirming their progenitor identity.

It is unclear whether cells surrounding the spinal cord CC are homogeneous in showing progenitor properties in vitro, or if these properties are only shared by a subset of spatially restricted cells. Microdissection experiments have suggested that neurosphere forming capabilities are mostly restricted to the dorsal portion of the spinal cord CC (Sabourin et al., 2009), a region where we observed the highest density of recombined Acc. Interestingly, although these cells represent a small populations of ependymal cells (that we estimated to be $<0.5 \%$ of all CC nuclei), they contributed to the formation of as many as $15 \%$ of all primary neurospheres. This suggest that only a subpopulation of CC, most likely residing in its dorsal most region, show neurosphere forming capacities (Martens et al., 2002; Sabourin et al., 2009). This dorsal region indeed contains most of the actively proliferating cells ( $\sim 80 \%$ of the $\mathrm{EdU}^{+}$cells, data not shown), further supporting heterogeneity of the CC.

We propose that the GFAP-expressing Acc described in this article represent a subpopulation of the previously described neurosphere-forming ependymal cells (BarnabeHeider et al., 2010; Meletis et al., 2008). Indeed, rare ependymal cells with clear radial morphology were observed to recombine in both the Foxj1-CreERT2 and NestinCreERT2 mice lines (Meletis et al., 2008). Our immunostaining results indeed confirmed Nestin expression in Acc recombined cells. Although we could not performed immunostaining for FoxJ1 due to a lack of a specific antibody, it should be noted that this marker is expressed in a subset of $\mathrm{SVZ} \mathrm{GFAP}^{+}$astrocytes of the adult SVZ (Jacquet et al., 2009). Following injury, SVZ FoxJ1-expressing astrocytes are activated and replenish the population of ependymal cells (Carlen et al., 2009; Jacquet et al., 2009). Our observation of a loss of polarity and increased densities of YFPexpressing cells in the regions of the CC close to the injury site (Fig. 6), suggests that a comparable regenerative process may occur in the SC. Future experiments based on split-Cre technology may allow addressing more in details the diversity and lineage relationship of cells types that populate the spinal cord CC.

Altogether, our work supports heterogeneity and regional distribution of stem/progenitor populations in the spinal cord CC. Rather than being a feature of a unique cell type, multipotent neurospheres formation is a property of two periaqueductal cell populations that differ according to GFAP expression and their in vivolin vitro proliferation potential. Our study identifies GFAP-expressing cells of the spinal cord as multipotent progenitors, by showing that only SVZ-recombined cells show the long-term self-renewal prop- erties of NSCs. These observations highlight major differences in the lineage of NSCs cells across the CNS neuraxis.

\section{Acknowledgment}

Grant sponsor: Neuroscience Centre Zurich, Swiss National Fund; Grant number: 31003A_127082 (PhD Fellowship to RF); The Christopher and Dana Reeve Foundation.

We are grateful to Dr Kasum Azim, Dr Michaela Thallmair and Dr Franz Obermair for critical reading of the manuscript. We would like to thank Anika Simon for technical assistance. The RIP antibody, developed by Prof S. Hockfield, was obtained from the Developmental Studies Hybridoma Bank developed under the auspices of the NICHD and maintained by The University of Iowa, Department of Biology, Iowa City, IA 52242. R.F. contributed to the conception and design, collection and assembly of data, data analysis and interpretation, and manuscript writing. A.C.S. and J.M.G.V. contributed to the collection and assembly of electron microscopy data. O.R. contributed to the conception and design, financial support, data interpretation, manuscript writing, and final approval of manuscript.

\section{References}

Alfaro-Cervello C, Soriano-Navarro M, Mirzadeh Z, Alvarez-Buylla A, GarciaVerdugo JM. 2012. Biciliated ependymal cell proliferation contributes to spinal cord growth. J Comp Neurol 520:3528-3552.

Anthony TE, Klein C, Fishell G, Heintz N. 2004. Radial glia serve as neuronal progenitors in all regions of the central nervous system. Neuron 41: 881-890.

Azim K, Fiorelli R, Zweifel S, Hurtado-Chong A, Yoshikawa K, Slomianka L, Raineteau O. 2012. 3-Dimensional examination of the adult mouse subventricular zone reveals lineage-specific microdomains. PLoS One 7: e49087.

Barnabe-Heider F, Goritz C, Sabelstrom H, Takebayashi H, Pfrieger FW, Meletis K, Frisen J. 2010. Origin of new glial cells in intact and injured adult spinal cord. Cell Stem Cell 7:470-482.

Beckervordersandforth R, Tripathi P, Ninkovic J, Bayam E, Lepier A, Stempfhuber B, Kirchhoff F, Hirrlinger J, Haslinger A, Lie DC, Beckers J, Yoder B, Irmler M, Götz M. 2010. In vivo fate mapping and expression analysis reveals molecular hallmarks of prospectively isolated adult neural stem cells. Cell Stem Cell 7:744-758.

Brewer GJ, Torricelli JR. 2007. Isolation and culture of adult neurons and neurospheres. Nat Protoc 2:1490-1498.

Carlen M, Meletis K, Goritz C, Darsalia V, Evergren E, Tanigaki K, Amendola M, Barnabe-Heider F, Yeung MS, Naldini L, Honjo T, Kokaia Z, Shupliakov O, Cassidy RM, Lindvall O, Frisén J. 2009. Forebrain ependymal cells are Notchdependent and generate neuroblasts and astrocytes after stroke. Nat Neurosci 12:259-267.

Chiasson BJ, Tropepe V, Morshead CM, van der Kooy D. 1999. Adult mammalian forebrain ependymal and subependymal cells demonstrate proliferative potential, but only subependymal cells have neural stem cell characteristics. J Neurosci 19:4462-4471.

Coles-Takabe BL, Brain I, Purpura KA, Karpowicz P, Zandstra PW, Morshead CM, van der Kooy D. 2008. Don't look: Growing clonal versus nonclonal neural stem cell colonies. Stem Cells 26:2938-2944.

Decimo I, Bifari F, Rodriguez FJ, Malpeli G, Dolci S, Lavarini V, Pretto S, Vasquez S, Sciancalepore M, Montalbano A, Berton V, Krampera M, 


\section{Fiorelli et al.: GFAP ${ }^{+}$Progenitors of the Adult Spinal Cord}

Fumagalli G. 2011. Nestin- and doublecortin-positive cells reside in adult spinal cord meninges and participate in injury-induced parenchymal reaction. Stem Cells 29:2062-2076.

Doetsch F, Caille I, Lim DA, Garcia-Verdugo JM, Alvarez-Buylla A. 1999. Subventricular zone astrocytes are neural stem cells in the adult mammalian brain. Cell 97:703-716.

Ganat YM, Silbereis J, Cave C, Ngu H, Anderson GM, Ohkubo Y, Ment LR, Vaccarino FM. 2006. Early postnatal astroglial cells produce multilineage precursors and neural stem cells in vivo. J Neurosci 26:8609-8621.

Garcia AD, Doan NB, Imura T, Bush TG, Sofroniew MV. 2004. GFAP-expressing progenitors are the principal source of constitutive neurogenesis in adult mouse forebrain. Nat Neurosci 7:1233-1241.

Golmohammadi MG, Blackmore DG, Large B, Azari H, Esfandiary E, Paxinos G, Franklin KB, Reynolds BA, Rietze RL. 2008. Comparative analysis of the frequency and distribution of stem and progenitor cells in the adult mouse brain. Stem Cells 26:979-987.

Hamilton LK, Truong MK, Bednarczyk MR, Aumont A, Fernandes KJ. 2009. Cellular organization of the central canal ependymal zone, a niche of latent neural stem cells in the adult mammalian spinal cord. Neuroscience 164:1044-1056.

Hirrlinger PG, Scheller A, Braun C, Hirrlinger J, Kirchhoff F. 2006. Temporal control of gene recombination in astrocytes by transgenic expression of the tamoxifen-inducible DNA recombinase variant CreERT2. Glia 54:11-20.

Hofstetter CP, Holmstrom NA, Lilja JA, Schweinhardt P, Hao J, Spenger C, Wiesenfeld-Hallin Z, Kurpad SN, Frisen J, Olson L. 2005. Allodynia limits the usefulness of intraspinal neural stem cell grafts; directed differentiation improves outcome. Nat Neurosci 8:346-353.

Hugnot JP, Franzen R. 2011. The spinal cord ependymal region: A stem cell niche in the caudal central nervous system. Front Biosci 16:1044-1059.

Jacquet BV, Salinas-Mondragon R, Liang H, Therit B, Buie JD, Dykstra M, Campbell K, Ostrowski LE, Brody SL, Ghashghaei HT. 2009. FoxJ1-dependent gene expression is required for differentiation of radial glia into ependymal cells and a subset of astrocytes in the postnatal brain. Development 136:4021-4031.

Kriegstein A, Alvarez-Buylla A. 2009. The glial nature of embryonic and adult neural stem cells. Annu Rev Neurosci 32:149-184.

Lledo PM, Merkle FT, Alvarez-Buylla A. 2008. Origin and function of olfactory bulb interneuron diversity. Trends Neurosci 31:392-400.

Malatesta P, Hack MA, Hartfuss E, Kettenmann H, Klinkert W, Kirchhoff F, Gotz M. 2003. Neuronal or glial progeny: Regional differences in radial glia fate. Neuron 37:751-764

Martens DJ, Seaberg RM, van der Kooy D. 2002. In vivo infusions of exogenous growth factors into the fourth ventricle of the adult mouse brain increase the proliferation of neural progenitors around the fourth ventricle and the central canal of the spinal cord. Eur J Neurosci 16:1045-1057.

Meletis K, Barnabe-Heider F, Carlen M, Evergren E, Tomilin N, Shupliakov O, Frisen J. 2008. Spinal cord injury reveals multilineage differentiation of ependymal cells. PLoS Biol 6:e182.

Merkle FT, Tramontin AD, Garcia-Verdugo JM, Alvarez-Buylla A. 2004. Radial glia give rise to adult neural stem cells in the subventricular zone. Proc Natl Acad Sci USA 101:17528-17532.

Mirzadeh Z, Merkle FT, Soriano-Navarro M, Garcia-Verdugo JM, AlvarezBuylla A. 2008. Neural stem cells confer unique pinwheel architecture to the ventricular surface in neurogenic regions of the adult brain. Cell Stem Cell 3: 265-278.

Mothe AJ, Tator CH. 2005. Proliferation, migration, and differentiation of endogenous ependymal region stem/progenitor cells following minimal spinal cord injury in the adult rat. Neuroscience 131:177-187.

Nam HS, Benezra R. 2009. High levels of Id1 expression define B1 type adult neural stem cells. Cell Stem Cell 5:515-526.
Obermair FJ, Fiorelli R, Schroeter A, Beyeler S, Blatti C, Zoerner B, Thallmair M. 2010. A novel classification of quiescent and transit amplifying adult neural stem cells by surface and metabolic markers permits a defined simultaneous isolation. Stem Cell Res 5:131-143.

Ohori Y, Yamamoto S, Nagao M, Sugimori M, Yamamoto N, Nakamura K, Nakafuku M. 2006. Growth factor treatment and genetic manipulation stimulate neurogenesis and oligodendrogenesis by endogenous neural progenitors in the injured adult spinal cord. J Neurosci 26:11948-11960.

Ohtsuka T, Imayoshi I, Shimojo H, Nishi E, Kageyama R, McConnell SK. 2006. Visualization of embryonic neural stem cells using Hes promoters in transgenic mice. Mol Cell Neurosci 31:109-122.

Ostrowski LE, Hutchins JR, Zakel K, O'Neal WK. 2003. Targeting expression of a transgene to the airway surface epithelium using a ciliated cell-specific promoter. Mol Ther 8:637-645.

Parras CM, Galli R, Britz O, Soares S, Galichet C, Battiste J, Johnson JE, Nakafuku M, Vescovi A, Guillemot F. 2004. Mash1 specifies neurons and oligodendrocytes in the postnatal brain. EMBO J 23:4495-4505.

Pfenninger CV, Steinhoff C, Hertwig F, Nuber UA. 2011. Prospectively isolated CD133/CD24-positive ependymal cells from the adult spinal cord and lateral ventricle wall differ in their long-term in vitro self-renewal and in vivo gene expression. Glia 59:68-81.

Platel JC, Gordon V, Heintz T, Bordey A. 2009. GFAP-GFP neural progenitors are antigenically homogeneous and anchored in their enclosed mosaic niche. Glia 57:66-78.

Reynolds BA, Weiss S. 1996. Clonal and population analyses demonstrate that an EGF-responsive mammalian embryonic CNS precursor is a stem cell. Dev Biol 175:1-13.

Robins SC, Stewart I, McNay DE, Taylor V, Giachino C, Goetz M, Ninkovic J, Briancon N, Maratos-Flier E, Flier JS, Kokoeva MV, Placzek M. 2013. alphaTanycytes of the adult hypothalamic third ventricle include distinct populations of FGF-responsive neural progenitors. Nat Commun 4:2049.

Sabelstrom H, Stenudd M, Frisen J. 2013. Neural stem cells in the adult spinal cord. Exp Neurol.

Sabourin JC, Ackema KB, Ohayon D, Guichet PO, Perrin FE, Garces A, Ripoll C, Charite J, Simonneau L, Kettenmann H, Zine A, Privat A, Valmier J, Pattyn A, Hugnot JP. 2009. A Mesenchymal-like ZEB1(+) niche harbors dorsal radial glial fibrillary acidic protein-positive stem cells in the spinal cord. Stem Cells 27:2722-2733.

Shihabuddin LS, Horner PJ, Ray J, Gage FH. 2000. Adult spinal cord stem cells generate neurons after transplantation in the adult dentate gyrus. J Neurosci 20:8727-8735.

Weiss S, Dunne C, Hewson J, Wohl C, Wheatley M, Peterson AC, Reynolds BA. 1996. Multipotent CNS stem cells are present in the adult mammalian spinal cord and ventricular neuroaxis. J Neurosci 16:7599-7609.

Wyszynski DF, Doetsch JP, Pugh EW, Bailey-Wilson JE. 1997. Comparison of selected methods used to analyze bipolar disorder. Genet Epidemiol 14:705710.

Yamamoto S, Yamamoto N, Kitamura T, Nakamura K, Nakafuku M. 2001. Proliferation of parenchymal neural progenitors in response to injury in the adult rat spinal cord. Exp Neurol 172:115-127.

Yang H, Lu P, McKay HM, Bernot T, Keirstead H, Steward O, Gage FH, Edgerton VR, Tuszynski MH. 2006. Endogenous neurogenesis replaces oligodendrocytes and astrocytes after primate spinal cord injury. J Neurosci 26: 2157-2166.

Zai LJ, Wrathall JR. 2005. Cell proliferation and replacement following contusive spinal cord injury. Glia 50:247-257. 